\title{
BIOÉTICA E INTERDISCIPLINARIDADE: a relação entre educação e meio ambiente
}

\author{
Marcos Alexandre Alves
}

\begin{abstract}
Resumo
O presente artigo tem por objetivo examinar os fundamentos epistemológicos da Bioética e relacioná-los às temáticas do meio ambiente e da educação. A literatura revisada mostra que esses temas são interdisciplinares e, portanto, podem ser considerados subjacentes e norteadores de um processo efetivo de formação humana voltado para a promoção da autonomia e da liberdade. Em âmbito metodológico, utilizou-se de uma pesquisa bibliográfica para desenvolver um estudo sistemático acerca da natureza e dos princípios da bioética e sua importância no campo educativo, da educação ambiental e formação do sujeito ecológico, da natureza e sociedade como espaço de cidadania e do desenvolvimento sustentável. Nesse sentido, defende-se uma educação direcionada à sustentabilidade e a ética do cuidado humanizado na relação com o Outro. O texto está organizado em três partes: inicialmente, aborda-se os aspectos históricos e conceituais da Bioética; na sequência, apresenta-se considerações a respeito da sustentabilidade ambiental; e, na parte final, discorre-se sobre aspectos éticos no campo da educação ambiental a partir das relações sociais e naturais do homem.
\end{abstract}

Palavras-chave: Bioética; Educação; Meio Ambiente.

BIOETHICS THE INTERDISCIPLINARITY: the relationship between education and theenvironment

\begin{abstract}
This article aims to examine the epistemological foundations of Bioethics and relate them to the themes of the environment and education. The revised literature shows that these themes are interdisciplinary and, therefore, can be considered as underlying and guiding an effective human formation process aimed at promoting autonomy and freedom. In a methodological context, a bibliographic research was used to develop a systematic study about the nature and principles of bioethics and its importance in the educational field, environmental education and the formation of the ecological subject, nature and society as a space for citizenship and the environment. sustainable development. In this sense, an education directed to sustainability and the ethics of humanized care in the relationship with the Other is advocated. The text is organized in three parts: initially, the historical and conceptual aspects of Bioethics are addressed; next, considerations about the environmental sustainability; and, in the final part, it discusses ethical aspects in the field of environmental education from the social and natural relations of man.
\end{abstract}

Keywords: Bioethics; Education; Environment.

\section{BIOÉTICA E INTERDISCIPLINARIDAD:} la relación entre educación y medio ambiente

Resumen

Este artículo tiene como objetivo examinar los fundamentos epistemológicos de la Bioética y relacionarlos con los temas del medio ambiente y la educación. La literatura revisada muestra que estos temas son interdisciplinarios y, por lo tanto, pueden ser considerados como subyacentes y orientadores de un proceso de formación humana efectivo dirigido a promover la autonomía y la libertad. Em âmbito metodológico, utilizou-se de uma pesquisa bibliográfica para desenvolver um estudo sistemático acerca da natureza e dos princípios da bioética e sua importância no campo educativo, da educação ambiental e formação do sujeito ecológico, da natureza e sociedade como espaço de cidadania e do desenvolvimiento sustentable. En este sentido, se aboga por una educación dirigida a la sostenibilidad y la ética del cuidado humanizado en la relación con el Otro. El texto está organizado en tres partes: inicialmente, se abordan los aspectos históricos y conceptuales de la Bioética; a continuación, se presentan consideraciones sobre el sostenibilidad del medio ambiente; y, en la parte final, discute aspectos éticos en el campo de la educación ambiental desde las relaciones sociales y naturales del hombre. 
Palabras clave: Bioética; Educación; Medio ambiente.

\section{INTRODUÇÃO}

Os problemas que afetam direta ou indiretamente as sociedades contemporâneas são de origens múltiplas e inter-relacionadas. Ora, para análise e o enfrentamento dessas questões é necessário utilizar-se de um referencial pautado em diferentes esferas do saber, a exemplo da Bioética. Como forma de abordagem, a Bioética se caracteriza pela inter, trans e multidisciplinaridade. Nessa perspectiva, um mesmo objeto ou tema pode ser estudado por diferentes disciplinas o que possibilita diálogo, intercâmbio, superação de barreiras e fronteiras entre os diferentes campos do conhecimento.

A Bioética passou a ter visibilidade a partir dos anos de 1970 em resposta à expansão e à aplicação de conhecimentos científicos e tecnológicos (DURAND, 2003). No século XXI, adquiriu identidade pública deixando de ser considerada uma questão de consciência privada a ser resolvida na esfera da autonomia individual ou apenas de foro íntimo. A saber, defende-se o alargamento da agenda da Bioética na qual são incorporados temas contemporâneos como as questões ambientais, a saúde pública, a engenharia genética, entre outros.

Cabe destacar que as mudanças genéticas possíveis em animais, vegetais e em humanos alteram o transcurso da história da humanidade e tudo isso tem a ver com a vida humana, a educação e com a organização social, política e econômica dos povos. Por isso, a abordagem de questões conflitantes da contemporaneidade também diz respeito aos processos educacionais que vão da Escola à Universidade. Esta, que tem por objetivo formar profissionais que irão atuar na sociedade, também reúne as possibilidades científicas e intelectuais necessárias ao ensino e à pesquisa. Em vista disso, tem uma responsabilidade ainda maior, porque, além de socializar os conhecimentos historicamente produzidos, deve auxiliar os estudantes a enfrentar os desafios impostos pelo avanço científico e tecnológico.

Entre os profissionais egressos das Universidades, o professor destaca-se pela singularidade do ofício: exerce funções de educar e ensinar. Ele ocupa um espaço/tempo específico na Escola ou Universidade, na sala de aula, que se constitui como o local onde o educador faz a mediação entre o conhecimento sistematizado e a aprendizagem dos estudantes.

O tema da interdisciplinaridade é uma questão que inquieta e desafia os atuais e futuros educadores, pela sua complexidade (MORIN, 2000). Em um sistema de ensino ainda tão engessado na disciplina, romper com os limites disciplinares é difícil, mas não impossível. Isso, porque entende-se que a interdisciplinaridade amplia a interação entre professores e alunos sem perder a especificidade do tema tratado. Ou seja, ela não anula as disciplinas, mas pede que as mesmas dialoguem entre si numa perspectiva educacional em busca de inovação. Considerando a rapidez com que ocorrem as mudanças na área do conhecimento e da produção, exigindo uma atualização contínua e colocando novas exigências para a formação do educando, é que a interdisciplinaridade se insere na ousadia de novas abordagens de ensino, na educação básica e, especialmente, nos cursos de formação de professores.

Percebemos, cada vez mais, que o caráter disciplinar do ensino formal dificulta a aprendizagem do aluno, não estimula ao desenvolvimento da inteligência, de resolver problemas e estabelecer conexões entre os fatos, conceitos, isto é, de pensar sobre o que está sendo estudado. Porém, em um projeto interdisciplinar é necessário determinar o valor de cada disciplina, seu nível teórico, suas estruturas e a intencionalidade de seu papel no currículo escolar ou acadêmico. Esses fundamentos possibilitam entender que a interdisciplinaridade é mais que uma simples integração de conteúdos. Para que ocorra a interdisciplinaridade não se trata de eliminar as disciplinas, mas de 
torná-las comunicativas entre si, concebê-las como processos históricos e culturais, necessária a atualização das práticas e do processo de ensino-aprendizagem.

A proposta da interdisciplinaridade visa estabelecer ligações de complementaridade, convergência, interconexões e passagens entre os conhecimentos. As atividades pedagógicas devem contemplar conteúdos e estratégias de aprendizagem que capacitem o aluno para a vida em sociedade, a atividade produtiva e experiências subjetivas, visando à integração. Ou seja, é importante enfatizar que a interdisciplinaridade supõe um eixo integrador com as disciplinas de um currículo, para que os alunos aprendam a olhar o mesmo objeto sob perspectivas diferentes. Assim, a prática interdisciplinar implica uma atitude permanente de crítica e reflexão, de compromisso e responsabilidade com a tarefa de educar. A postura que os educadores devem adotar diante das mudanças na educação deve ser: pensar, refletir, criticar e valorar o que está acontecendo nos âmbitos escolares presentes e futuros. Portanto, a interdisciplinaridade impõe aos educadores a exigência de um aperfeiçoamento, em busca da melhora da educação, o que exige uma reflexão profunda por parte de todos aqueles que terão de uma forma ou de outra, responsabilidades específicas na formação de novas gerações.

Nesse sentido, o presente artigo tem por objetivo examinar os fundamentos epistemológicos da bioética e relacioná-los com aspectos do meio ambiente e a educação. A relevância deste trabalho reside no fato de que se constata na literatura atual carência de estudos que tratam as questões educacionais e ambientais, a partir de parâmetros da bioética ou ética aplicada.

Em âmbito metodológico, utilizou-se de uma pesquisa bibliográfica para desenvolver um estudo sistemático acerca dos seguintes temas: natureza e princípios da bioética, ética para a civilização tecnológica, a questão da ética no campo educativo, ética ambiental e educação ambiental, formação do sujeito ecológico, saúde e ambiente sustentável, natureza e sociedade como espaço de cidadania, desenvolvimento e meio ambiente, educação ambiental na escola, sociedade e meio ambiente, a formação dos educadores ambientais. Para dar o devido aprofundamento conceitual e temático buscou-se amparo teórico nas obras dos seguintes autores: Beauchamp; Childress (2002), Potter (1971; 2001), Imbert (2001), Jonas (2006), Durand (2003), Grün (2005), Morin (2000), Carvalho (2004), Guimarães (2004), Layrargues (2000), Layrargues; Puggian (2018), Loureiro (2007), Minayo (2002), Orellana; Suavé (2001), Pelicioni (2005).

As três partes em que este texto está organizado visam contribuir para o aprofundamento da reflexão sobre o tema. Inicialmente, aborda-se os aspectos históricos e conceituais da Bioética. $\mathrm{Na}$ sequência, são apresentadas considerações a respeito de meio ambiente e, na parte final, discorre-se sobre aspectos éticos no campo da educação ambiental a partir das relações homem, sociedade e natureza. Nas considerações finais retoma-se o tema de estudo com base nos parâmetros da bioética.

\section{ASPECTOS HISTÓRICOS E CONCEITUAIS DA BIOÉTICA}

Historicamente, a Bioética surge a partir das discussões relativas à ética médica, já que desta última ciência se ergueu o estudo da decisão moral no campo médico. A ética médica centrava-se na relação médico-paciente, na qual o médico decidia tudo, principalmente sobre aquilo que ele acreditava ser bom para o seu paciente. Raramente levava-se em consideração os interesses e anseios dos pacientes e familiares. Esse tipo de postura, por parte do médico, produziu uma espécie de cultura, na área da medicina, que pode ser denominada de paternalista. Esse modelo, em que impera o poder e a autoridade do médico, começa a ser colocado em questão, a partir dos anos 
1970, pela Bioética, como uma abordagem secular, interdisciplinar, prospectiva, global e sistemática (CLOTET, 2003).

A abordagem da Bioética se deu, segundo Anjos (2001), por meio de uma nova tomada consciência: por um lado, teólogos, conscientes de viver em um mundo pluralista, e da necessidade de discutir questões que interessavam a todos os cidadãos, sentiram que não podiam se fechar em uma perspectiva totalmente religiosa, e que precisavam secularizar a sua linguagem e argumentação; e, por outro lado, percebendo sua implicação nas questões discutidas, intervieram médicos, filósofos, juristas, sociólogos, economistas, legisladores e um conjunto de cidadãos. Nessa mesma perspectiva, a Bioética pretende para si, também, uma abordagem interdisciplinar, em que se privilegia a colaboração e a interações das diversas ciências para analisar as questões concretas do mundo da vida e assim encontrar soluções adequadas. Uma terceira característica da Bioética é sua visão prospectiva, pois as regras tradicionais não respondem satisfatoriamente às demandas sociais que são cada vez mais complexas e que demandam novos patamares da discussão e de reflexão, a fim de encontrar soluções adequadas à situação atual e até permissíveis para o futuro.

Essas três características da Bioética, na leitura de Durand (1995), viabilizam as condições necessárias para se fazer uma abordagem global e integral da pessoa, da cultura e da sociedade na qual ela está inserida. A Bioética se interessa pela decisão pessoal, pelo diálogo interpessoal, pelas estruturas sociais e legais e pelas regras e valores dados pela sociedade. E, por último, faz uma abordagem sistemática e não se limita a solucionar problemas isolados uns dos outros, sem ligação ou coerência. Portanto, Bioética é, por um lado, uma análise rigorosa e lógica; por outro, busca a coerência na solução de diversos problemas morais.

Atribui-se a Potter, em 1971, ter cunhado e divulgado a palavra Bioética. Inicialmente, o sentido atribuído por Potter (1971) à Bioética referia-se a importância das ciências biológicas na melhoria da qualidade de vida e à sobrevivência do planeta. Posteriormente, Potter defende que a Bioética é uma nova ética científica, que combina humildade, responsabilidade e competência, numa perspectiva interdisciplinar e intercultural que potencializa o sentido da humanidade. Ou seja, Potter defende uma "bioética global, como uma nova ciência ética, é uma necessidade para a sobrevivência a longo prazo" (2001, p. 337). Essa nova racionalidade ética conduz à constituição da subjetividade humana, da formação do homem e do seu projeto de viver, neste mundo, em harmonia consigo mesmo, com os demais e a natureza. Nesse sentido, entende-se que a Bioética, pode ser um instrumento a serviço do cultivo do desenvolvimento humano; pode apoiar o homem, despertá-lo e estimulá-lo para que consiga reconhecer-se na sua própria humanidade; pode ajudálo a descobrir seu próprio lugar no mundo, a conseguir a estima de si mesmo e assumir a responsabilidade para com o futuro da vida no planeta.

Diante de questões emergentes decorrentes das novas descobertas científicas, no campo da biotecnologia, da clonagem biológica e da problemática ambiental, as respostas oferecidas pela moral não são suficientes: nesse viés situa-se a Bioética. Pode-se entender então que, a reflexão crítica a partir dos fundamentos epistemológicos da Bioética, é provocada e estimulada pelas questões que se apresentam a cada novo conhecimento gerado pelas ciências ou possibilitado pelo uso de novas tecnologias, ou seja, a partir dos problemas que se apresentam no cotidiano social e ambiental.

Atualmente, a Bioética é um assunto que perpassa todos os níveis da vida e envolve todos os setores de nossa sociedade, tais como as áreas da saúde, da política, da sociologia, da economia, da ecologia, da educação (PELICIONI; PHILIPPI, 2005). Ela faz parte do nosso dia-a-dia, e a sua reflexão começa a interferir sempre mais em nossas vidas. Ou seja, a preocupação com a Bioética está presente em toda sociedade. Não porque lhe seja dedicada maior estima ou particular fidelidade, mas porque sentimos sua falta. Generaliza-se o sentimento de que a vida humana e a 
sociedade precisam ser revistas à luz da Bioética, sob pena de se caminhar sem rumo para os maiores desastres, senão para o completo caos, perdendo a possibilidade de ser feliz e de alimentar a esperança de um mundo de paz e justiça, não só nós hoje, mas para as gerações futuras. Como enfrentar a atual carência ética? Acredita-se que há um caminho que não pode ser negligenciado, quando se busca construir um mundo humano, uma sociedade ética: a educação. Como, porém, educar eticamente? Será que, no campo pedagógico da formação de novos professores, existe lugar para a questão de Bioética? A pedagogia poderia ser confrontada com um questionamento e com um engajamento bioético? O que preside as atividades pedagógicas? Qual o princípio imediato que sustenta e exprime a qualidade em educação?

A passagem rápida pelos desafios que emergem de nossa epocalidade histórica e educacional nos confirma a necessidade de encontrar uma nova configuração para o saber, a fim de se confrontar com um mundo marcado pela primazia do técnico. Nesse cenário em que se constata a crise do saber, da subjetividade, do humanismo e da ecologia, cabe a Bioética, em particular, ao seu ensino, responder e proporcionar com esforço a reconstrução da dimensão crítica do saber humano (CLOTET, 2003). A educação precisa colocar como preocupação fundamental o desenvolvimento de um processo efetivo de humanização. Isto é, proporcionar ao homem um quadro referencial básico, em que ele possa situar-se de modo responsável e livre ao agir no mundo. Ao longo da história do pensamento ocidental, na perspectiva de Imbert (2001), muitos foram os pensadores que se propuseram definir "ética" e "moral", e a grande maioria deles costumava afirmar que a moral é um conjunto de regras aceitas livre e conscientemente pelo homem em sociedade, ou seja, a moral implica um padrão de conduta, de comportamento que indica e convida o homem a viver e fazer o bem, enquanto que a ética seria uma ciência, uma teoria, um saber, portanto uma reflexão sobre as questões e os problemas morais. Já a Bioética, para Potter (1971), não quer ser considerada como uma ciência, disciplina ou movimento social, mas uma dinâmica reflexiva que procura resgatar a dignidade da pessoa humana e sua qualidade de vida desde o nível "micro" até o "macro".

Por conseguinte, ao se trabalhar com questões de Bioética impõe-se ter presente uma análise racional sobre o comportamento humano, isso não implica apenas uma reflexão desvinculada do mundo circundante: ela é uma teorização sobre a prática, sobre práxis, sobre a vida, e não só sobre a vida ideal, mas sobre a vida real, como é e como realmente poderia ser.

A partir dessas ideias preliminares torna-se oportuna e necessária uma reflexão crítica sobre a ética na vida do professor (IMBERT, 2001). Quem é um verdadeiro professor? Qual é a identidade? Qual é o papel social atribuído ao professor pela sociedade contemporânea? Não se é professor apenas ocasionalmente, por algum acidente, mas profissionalmente, vale dizer, vive-se a tarefa do ensino como profissão. Ensinar é trabalho para o qual o professor se sente preparado, via formação específica, trata-se de profissão com função eminentemente social, que serve à comunidade, em que se está inserido desde o nascimento.

Uma possível tentativa de resposta propositiva, a esses questionamentos, poderia ser esboçada a partir da área da Ética aplicada, mais especificamente da Bioética, que tem produzido uma reflexão muita rica e profunda, nos últimos 50 anos. A Bioética é uma reflexão que faz uma ponte entre os conhecimentos científicos, inicialmente mais vinculada à área da saúde, mas hoje aberta às todas as áreas do conhecimento humano: ciências humanas; sociais aplicadas; tecnológicas e os valores filosóficos (BEAUCHAMP; CHILDRESS, 2002).

O destinatário desta nova proposta ético-formativo é o homem, porque é ele que constrói sua vida no mundo; é o homem que se desenvolve e amadurece como humano, em harmonia consigo mesmo, com os demais e com a natureza. Desse modo, a Bioética pode ser um instrumento a serviço do cultivo do desenvolvimento humano; pode apoiar o homem, despertá-lo e estimulá- 
lo para que consiga reconhecer-se na sua própria humanidade; pode ajudá-lo a descobrir seu próprio lugar no mundo, a conseguir a estima de si mesmo, do outro e da natureza. Portanto, a missão da Bioética é (re)significar o papel dos valores fundamentais na educação, como estímulo potencial para o melhoramento humano no ambiente em que vive, nessa hora da humanidade em que o homem se pergunta pelo sentido de sua passagem na terra (ALVES, 2016).

Nos últimos anos, o mundo mudou rapidamente. A ciência, a tecnologia, a economia, a política e a ideologia, tudo está mudando de maneira vertiginosa, e nessa mudança toda, pela qual passa o mundo, o homem permanece desorientado, tentando reconhecer-se e encontrar valores que orientem o seu pensar e agir. Em um mundo de mudanças rápidas, parece que o único consenso, em termo de objetivo, entre os povos é a busca pelo chamado "desenvolvimento" que passa, inevitavelmente, pelo aprimoramento tecnológico e industrial, até aí nenhum problema. No entanto, o problema se manifesta quando esse ideal "desenvolvimentista" aparece como referencial e único estilo de vida, pelo qual o homem poderá atingir o ápice da liberdade pessoal, da modernização e do poder (POTTER, 2001).

A Bioética surge, na perspectiva de Potter (1971), neste contexto, como uma voz e um alerta para uma reflexão profunda sobre os perigos de uma concepção em que o homem seja educado apenas para produzir e consumir, mais do que para viver uma vida plena e harmônica; para "ter" mais e não para "ser" mais. Nesse sentido, o grande convite feito pela Bioética, neste momento em que o homem se embriaga com os poderes de uma ciência e uma tecnologia que ele mesmo criou, e se sente seduzido pela riqueza, a notoriedade e os prazeres; em que recorre a serviços e recursos artificiais, porque não encontra a si mesmo, vislumbra-se uma tendência para um subjetivismo sadio em que o homem reedita para si, sem sabê-lo, o clássico "conhece-te a ti mesmo"; o homem tenta perguntar-se sobre o "humano". Da mesma forma que o homem se redescobre como ser humano, mesmo que pareça um paradoxo, começa a descobrir a alteridade.

Portanto, a intenção desse texto é demonstrar, a partir da Bioética, a necessidade de uma aproximação e interpenetração da ética, das ciências e as questões ambientais, num esforço sinérgico de busca e reflexão do humano. Há perguntas mais profundas quando se fala do valor da educação e da Bioética, que os educadores devem colocar com sinceridade: é hoje legítima e realista a aspiração de situar o homem na categoria de pessoa racional, imaginativa, criadora, consciente, reflexiva, cultivada e desenvolvida sobre a individualidade instintivo-animal? Que crianças, jovens e adultos se quer formar: objetos que consomem ou se consomem no desfrute e no prazer apenas do material? Ou, sujeitos que harmonizem sua existência e encontrem a felicidade na realidade de seres integrais?

Acredita-se que a Bioética pode apresentar respostas à interrogação do "para quê" da educação e sustentá-las com responsabilidade a partir da (re)significação dos valores éticos fundamentais. Desde as sociedades primitivas houve múltiplas maneiras de se tentar uma educação efetivamente humana. Um projeto concreto para atender a essa problemática deve propor-se a: ensinar sobre culturas dos diferentes com o objetivo de aproximar os homens na mutua compreensão; ensinar também sobre os direitos humanos; e, ensinar sobre a urgência de preservar o meio ambiente.

\section{MEIO AMBIENTE, TÉCNOLOGIAS E RESPONSABILIDADE: EM DEFESA DA CIDADANIA AMBIENTAL}

As questões ambientais são multifacetadas, e estão diretamente relacionadas à manutenção da saúde da população. Atualmente a discussão sobre o conceito de saúde remete ao tema da sustentabilidade ambiental. Conforme Minayo e Miranda (2002), já na metade do século XIX o 
conceito de saúde era articulado com a questão social, com a problemática do saneamento básico e com a formulação de políticas públicas, porém a chamada revolução bacteriana, que trouxe grandes benefícios para a humanidade, provocou um retrocesso no pensamento da medicina social. As descobertas das doenças e de meios de imunização levaram a pensar que todas as enfermidades poderiam ser erradicadas. A partir da Segunda Guerra Mundial retoma-se o pensamento social sobre a saúde. Nesse sentido, para Sawaia (2003) as Ciências Humanas e setores da saúde como a Saúde Coletiva, têm papel decisivo na denúncia do sentido exclusivamente biológico e da necessidade de tirar a saúde de estado da natureza e inseri-la como uma questão subjetiva, social e cultural. Conforme o autor, atualmente ninguém discorda que a pobreza, as condições de trabalho, de higiene, de moradia, os costumes e as práticas de saúde, a representação da doença, são fatores intervenientes no processo da saúde e da doença.

Nessa perspectiva, Freitas e Porto apontam que, um dos grandes dilemas da questão ambiental, está relacionado à forma de produção científica que tende a subdivisão do conhecimento em especialidades, isolando cada vez mais o objeto de estudo: "as várias disciplinas científicas foram se desenvolvendo por meios de paradigmas que recortam excessivamente a realidade e não se comunicam entre si, formando comunidades fechadas de especialistas em torno dos paradigmas hegemônicos, sendo esta a característica básica da ciência normal" (2006, p. 30). Essa fragmentação do conhecimento dificulta a visão do todo e impede entender o processo saúde-doença como multicausal. Com isso, para entender o processo saúde-doença é preciso ver todo o processo e não as partes segmentadas, ou seja, ter uma visão contextualizada dos fatos.

O desenvolvimento científico propicia que o homem se sinta onipotente e pense que conseguirá superar todos os problemas que vão surgindo, porém a realidade se mostra diferente, apesar do avanço tecnológico, doenças que já haviam sido controladas voltam a atacar (reemergentes) e ainda surgem novas doenças (emergentes), algumas delas ainda incuráveis. Tratase do paradoxo mencionado por Garrafa (2003) em mantemos um pé no século XIX e o outro no século XXI, ou seja, ao mesmo tempo em que se detém desenvolvimento tecnológico e científico ainda se enfrenta antigos problemas como a falta de saneamento básico e incapacidade de acabar com doenças como a malária.

O modelo vigente de desenvolvimento econômico, o acelerado avanço científico, a depredação do meio ambiente são fatores, entre outros, segundo Jonas (2006), relevantes para o entendimento e garantia da qualidade de vida das pessoas da nossa geração e das gerações futuras. Alguns autores vêm trabalhando o conceito de precaução frente às incertezas e riscos tecnológicos. Vermersch e Matthee (2002) destacam que a aplicação do princípio da precaução constitui a partir de hoje, uma passagem obrigatória na gestão dos riscos tecnológicos e do meio ambiente. Relacionando o tema com os organismos transgênicos (OGM) os autores acrescentam que na Europa o princípio da precaução recobre as áreas de meio ambiente, alimentação e saúde humana, fazendo lembrar a profunda imbricação entre elas.

Para se abordar o tema da prevenção e precaução faz-se necessário uma comparação em relação ao modo como eram tratadas as questões ambientais do século XX e como passam a ser tratados atualmente. Antes, os problemas ambientais eram analisados e regulamentados sob a ótica do paradigma preventivo clássico, os riscos podiam ser passíveis de conhecimento e controle, o aprimoramento contínuo do conhecimento tecno-científico daria conta de possíveis transtornos eventualmente revelados pela emergência de desastres e casos de doenças. Este paradigma baseavase no otimismo tecnológico e a tendência na redução das incertezas ao nível de riscos aceitáveis e controláveis. No entanto, para Freitas e Porto "as mudanças ocorridas nas últimas décadas, com a emergência do novo paradigma 'precaucionário', estão relacionadas ao crescente reconhecimento de novos graus de complexidade e incertezas dos riscos tecnológicos modernos..." (2006, p. 35). 
Nesse sentido, passa-se da prevenção de riscos causados pelas novas tecnologias e sua aplicação sempre que se julgasse que os benefícios seriam maiores, para o princípio da precaução diante das incertezas quanto aos riscos que essas novas tecnologias podem provocar e que podem ser bem elevados (mortes, doenças, depredação ambiental).

Uma discussão como essa, segundo Vermersch e Matthee (2002), deve incluir, além do saber científico, o poder público e a responsabilidade individual. Muitas discussões vêm sendo desenvolvidas no intuito de preservar o meio ambiente e promover o desenvolvimento sustentável. Entre as propostas está o enfoque ecossistêmico de saúde humana descrito por Minayo e Miranda (2002). Esta proposta leva em consideração os aspectos sociais, econômicos e ecológicos, valorizando igualmente esses três componentes para o desenvolvimento sustentável. Ela nasceu com a observação e a consciência ecológica de americanos e canadenses em relação à área dos Grandes Lagos entre o Canadá e os Estados Unidos. Essa região foi invadida por projetos agrícolas e industriais em função do acelerado progresso econômico americano. Com isso foram criadas estratégias transdisciplinares e participativas de atenção à problemática que afetava toda essa região. Assim, iniciou-se uma abordagem ecossistêmica, integrando saúde e ambiente, de modo que ciência e mundo da vida se unam na construção da qualidade de vida através de uma melhor gestão do ecossistema e da responsabilidade individual e coletiva sobre a saúde.

Outro aspecto interessante a se considerar é a noção de cidadania ambiental defendida por para reequilibrar o ambiente de vida para a sociedade. Waldman defende que a difusão do conceito de "responsabilidade ambiental" é importante, pois é inseparável da noção de cidadania ambiental; "o meio ambiente é um bem coletivo, não podendo a qualquer pretexto, desvincular-se desse paradigma. Desta forma, nada mais coerente do que uma visão abrangente de cidadania, configurada em responsabilidades compartilhadas difundidas nos mais diversos recortes sociais, políticos e econômicos" (2003, p. 555). Acrescenta ainda que para qualquer ação efetiva de conservação da natureza e de objetivação da cidadania ambiental são indispensáveis três esferas de atuação conjunta: a administração pública (federal, estadual e municipal); a sociedade e o cidadão. A responsabilidade compartilhada só pode se tornar concreta pela criação de parcerias sociais entre esses três níveis atuando conjuntamente para a resolução dos problemas ambientais. No âmbito do poder público é necessário que o Estado disponha de capacidade de intervenção através de políticas públicas; a questão ambiental não se resolve com um Estado fraco e sim com um Estado atuante; um "Estado mínimo" favorece a degradação ambiental. Quanto à sociedade, citam-se as cooperativas de reciclagem, escolas e associações comunitárias da periferia, sindicatos que incluem nas reivindicações qualidade de vida e segurança no trabalho, entre outros. Em relação ao nível individual, considera-se esse de maior importância e não pode ser desmerecido por uma estratégia ambiental, porque a cidadania ambiental tem nos indivíduos seu suporte objetivo (LAYRARGUES, 2000).

\section{MEIO AMBIENTE E EDUCAÇÃO: QUESTÕES EMERGENTES EM BIOÉTICA}

A partir das últimas três décadas do século $\mathrm{XX}$, quando se revelaram a amplitude, a gravidade e a aceleração crescente dos problemas socioambientais. O tema meio ambiente tem ocupado a pauta central de discussão em diversos setores da sociedade e no contexto educacional (ALVES; ROCHA ALVES, 2012).

A visão antropocêntrica, com raízes no pensamento cartesiano, é apontada como uma das causas que levou o homem a se colocar fora e distante do seu meio natural evidenciando-se uma dicotomia nas relações homem/sociedade/natureza. Nessa concepção, o valor dos recursos 


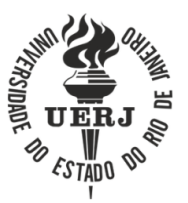

DOI:10.12957/teias.\%Y.54617

naturais está em sua utilidade para o homem que tem direito e posse sobre os mesmos (SAUVÉ, 2005).

Para Grün, na esteira do cartesianismo, encontra-se representado o "ideal de autonomia do sujeito e o afastamento dos indivíduos em relação ao solo e a terra" (2005, p. 95). Nesse sentido, a ética ambiental está relacionada com questões históricas, sociais e com os pressupostos filosóficos que surgiram ao longo da evolução da relação homem/natureza. Dessa interação resultou também a organização social.

As diferentes formas de organização sociais estão estritamente associadas à capacidade humana de estabelecer relações. Essa capacidade constitui a dimensão relacional que, por sua vez, fundamenta-se em visões de mundo. Essas visões são a base de referência para o relacionamento humano com o mundo, o que inclui a relação humana com a natureza, com as instituições, com as outras pessoas, as coisas e tudo o que existe e faz parte do ambiente.

Nesse sentido, Cobern (1996) argumenta que as visões de mundo são individuais, culturalmente dependentes e socialmente construídas. Isso significa que as visões de mundo emergem das relações que os seres humanos estabelecem entre si, com o ambiente não humano e com a própria organização social. Estão ligadas a uma determinada época e a civilizações específicas, de maneira que é possível concebê-las numa perspectiva histórica e de mudança. As mudanças pressupõem ruptura e/ou reorganização de alguma forma de conhecimento para que novas visões de mundo sejam concebidas. Essas acontecem a partir das experiências vivenciadas, possibilitam novas compreensões e, por decorrência, o avanço do conhecimento.

Por conseguinte, o argumento que se coloca é de que a interpretação e as relações que o sujeito estabelece com a realidade socioambiental são decorrentes de suas visões de mundo. Constituindo-se em num quadro epistêmico mais amplo que favorece a compreensão da natureza humana, da organização social e do funcionamento das próprias leis da natureza, permitindo compreender a realidade com base em uma racionalidade, ou seja, ter uma explicação ou uma justificativa para pensamento e ação. Sendo subjetivas, as visões de mundo são construídas a partir da percepção que o sujeito tem da realidade, mas pressupõem normas e valores culturalmente definidos.

$\mathrm{Na}$ compreensão das relações entre sociedade e natureza, se tem presente o meio ambiente que remete as ideias de vida biológica, vida selvagem, fauna e flora. Essa concepção se filia a uma visão de educação ambiental denominada naturalista que se baseia principalmente na percepção da natureza como fenômeno estreitamente biológico, autônomo, alimentando a ideia de que há um mundo natural constituído em oposição ao mundo humano. Como também, é aquilo que deveria permanecer fora do alcance do ser humano.

A tradição naturalista de educação ambiental foi superada pela visão socioambiental. A natureza e os homens, bem como a sociedade e o ambiente, estabelecem uma relação de mutua interação, que tem como objetivo repensar a ideia de evolução, percebendo como interação entre a natureza e a as espécies que vão surgindo; esse processo interativo é denominado coevolução. A partir disso, para Carvalho (2004), há uma dicotomia entre a natureza e a sociedade, para poder ver as relações de interação permanente entre a vida humana social e a vida biológica da natureza. A visão socioambiental orienta-se por uma racionalidade complexa e interdisciplinar que concebe o ambiente não como sinônimo de natureza intocada, mas como um campo de interação entre a cultura, a sociedade a base física e biológica dos processos vitais, no qual todos os termos dessa relação se modificam e se influenciam mutuamente.

Sendo subjetivas, as visões de mundo são construídas a partir da percepção que o sujeito tem da realidade, mas pressupõem normas e valores culturalmente definidos. Os costumes são entendidos como o primeiro conteúdo da cultura humana e referem-se à maneira de viver e ao 
comportamento, segundo os princípios em uso de uma sociedade. No entanto, muitos costumes tornaram-se universais e são aplicados a todas as civilizações porque manifestam aspectos importantes da existência humana como os valores à vida.

Orellana e Sauvé (2001) apresentam uma visão de meio ambiente mais abrangente se comparada ao descrito anteriormente. Para essas autoras, o meio ambiente pode ser considerado como natureza para ser apreciada, respeitada e preservada; como sistema onde se faz necessário compreender para tomar melhores decisões; como meio de vida a qual conhecê-lo é uma forma de poder organizá-lo; pois é entendido como um lugar de identidade cultural; como recurso, para gerir e repartir; como problema que precisa ser prevenido e resolvido; como lugar em que se vive, portanto deve ser conhecido e aprimorado; como biosfera, onde se pode viver juntos e a longo prazo; enfim, é o lugar da solidariedade internacional que nos leva a refletir mais profundamente sobre os modos de desenvolvimento das sociedades humanas.

À visão socioambiental, alinha-se a corrente de educação para a sustentabilidade ou desenvolvimento sustentável. Nessa perspectiva, Jonas (2006) defende que o desenvolvimento sustentável seja fundamentado nos princípios ecológicos básicos do ecossistema e na ética ambiental, o que significa compreender um conjunto de valores como autonomia, solidariedade e responsabilidade com as questões socioambientais. Do mesmo modo, Loureiro (2007) defende que as relações homem-natureza, devem ser pautadas em princípios éticos para promover a sustentabilidade dos ecossistemas naturais e dos sistemas sociais, sobre os quais as ações humanas são determinantes.

Em interessante estudo apresentado por Layrargues e Puggian (2018), as principais características da educação para a sustentabilidade estão descritas em variáveis apresentadas a seguir. Na variável contextual, para enfrentar as crises da modernidade, a educação para a sustentabilidade deve ser engajada e baseada na comunidade e nos contextos econômico, social e ecológico local, ampliando-se para uma visão regional, nacional, internacional e global. A educação para a sustentabilidade fundamenta-se na ideia que inclui as inter-relações entre diversas áreas do conhecimento, como a ciência, a economia, a política, a ética, entre outras, e visa oferecer discernimento e orientação para um futuro humano seguro e ambientalmente sustentável.

A educação para a sustentabilidade é prospectiva e tem por base a equidade social. Centrase no desenvolvimento social e na ecologia humana, mas não se limita a esses aspectos, porque tem uma abordagem holística e conectada às diversas áreas. Sendo holística e humana, reconhece que todas as dimensões educacionais, do currículo escolar ao comportamento humano, se afetam mutuamente e precisam ser vistos como um todo. Com enfoque no desenvolvimento da pessoa humana, considera as necessidades dos estudantes e dos professores. É também integrativa, porque tem por base o questionamento interdisciplinar do conhecimento, admitindo que nada existe isoladamente. Essa concepção educacional, segundo Morin (2000), considera a superação das tradições disciplinares para dar novos significados, entendimentos e modos de trabalhar temas comuns que ultrapassam a própria disciplina, como, por exemplo, o meio ambiente.

Esse processo educacional emancipador e participativo, entende a educação e a aprendizagem como dimensões inerentes à vida humana. Aqui, a ênfase está no aprender, não no ensinar. Propõe atividades centradas na reflexão crítica, como pesquisa-ação, ciclos de aprendizagem experiencial, entre outras. Trata-se de um processo crítico, porque parte do princípio de que nenhum valor educacional é politicamente neutro. Fundamenta-se nas teorias críticas do conhecimento associadas às orientações ambientalistas da atualidade. Por fim, esse modelo de educação ambiental está amparado nos valores bioéticos, porque tem presente a racionalidade que relaciona e torna indissociáveis o pessoal e o coletivo, estendendo a fronteira do cuidado e da preocupação para além da dimensão subjetiva (ALVES, 2016). Esse sentido requer senso 
participativo e solidariedade com as outras pessoas, ambientes e espécies destas e das futuras gerações.

A educação para a sustentabilidade deve ser alimentada com todas as formas de pensamento, em busca de um bem comum (JICKLING, 1992). Essa proposta não é prescritiva, mas sim indicativa, que visa resgatar a compreensão das organizações da sociedade, na relação homem-natureza. Como processo educacional, objetiva a preparação dos indivíduos a perceberem que as relações sociais e econômicas, construídas pela humanidade, devem ser justas e devem considerar a finitude dos recursos naturais existentes na Terra.

Apesar de a educação para a sustentabilidade ter sido difundida a partir da década de 1990, ter conquistado adeptos e espaço entre educadores ambientais, o tema não se esgota nas posições daqueles que a defendem. GUIMARÃES (2004), argumenta que é preciso pensar e promover a educação como um todo e que pode parecer estranho abordar a educação ambiental de modo não consistente com um conceito mais amplo de educação. Sobre a formação dos jovens, defende que o papel da educação é desenvolver a autonomia de pensamento e de ação, numa perspectiva de posicionamento diante das posições conflitantes geradas pela sociedade atual.

No que se refere à necessidade de superar a visão ingênua de educação ambiental, segundo Carvalho, a educação ambiental passou a ser empregada como termo genérico para tudo aquilo que se aproximaria de "boas práticas ambientais" ou "bons comportamentos ambientais" (2004, p. 153). Na perspectiva ingênua, a educação ambiental não considera a complexidade dos problemas sociais e os diferentes modos de acesso aos bens ambientais que, mesmo garantidos pela Constituição Federal de 1988 como de uso comum, são disputados por interesses particulares em detrimento dos interesses coletivos. Para Carvalho, "apenas uma visão ingênua tenta sugerir que a boa intenção de respeitar a natureza seria premissa suficiente para fundamentar nova orientação educativa apta a intervir na atual crise ecológica" (2004, p. 154). Nesse sentido, a educação ambiental é uma proposta educativa que nasce em um momento histórico de alta complexidade. Faz parte de uma tentativa de responder aos sinais de falência de todo modo de vida, o qual já não sustenta as promessas de felicidade, afluência, progresso e desenvolvimento (LAYRARGUES; PUGGIAN, 2018).

Segundo Loureiro (2007), essas dimensões abarcam os postulados da educação para a sustentabilidade, da educação ambiental crítica e as demais denominações. Isto é, Loureiro deixa implícita a necessidade de propostas educacionais consistentes, ao explicar que a educação ambiental surge como alternativa pedagógica, num momento em que os processos educativos tornaram-se insuficientes para dar respostas às exigências humanas e sociais da contemporaneidade. Soma-se a isso, a necessidade de profissionais bem preparados, capazes de perceberem os problemas que afetam as sociedades para discuti-los criticamente com seus alunos. A educação ambiental situa-se na confluência do campo ambiental com a Bioética.

Considera-se que todos esses aspectos estão relacionados com os processos educativos, nos diferentes níveis de ensino, uma vez que, tanto a escola como a universidade, precisam introduzir os estudantes no contexto do debate bioético com o objetivo de fomentar, por meio de procedimentos argumentativos e dialógicos, a sensibilidade para as questões morais e a formação de uma subjetividade como fórum de decisões práticas.

\section{CONSIDERAÇÕES FINAIS}

O objetivo geral do trabalho foi examinar os fundamentos epistemológicos da Bioética e relacioná-los às temáticas do meio ambiente e da educação. Procurou-se analisar a luz de referências pertinentes que permitiram elaborar as seguintes considerações referentes ao tema de estudo: a) $O$ 
meio ambiente e determinados aspectos relacionados à saúde humana podem ser concebidos como questões emergentes no campo da Bioética. Observa-se que o debate contemporâneo acerca destes temas não abandonou os princípios da ética tradicional subjacente a questões persistentes da Bioética, como o aborto e a eutanásia. Isto significa que valores como a fraternidade, a alteridade e o respeito a todas as formas de vida são preservados e devem pautar a reflexão crítica sobre as consequências dos avanços da ciência e da tecnologia uma vez que, o uso inadequado tanto da ciência como da tecnologia, poderá abreviar algumas formas de vida e, em muitos casos, gerar degradação ambiental; b) Em relação à educação constata-se a necessidade de uma aproximação e interpenetração da ética, ciência e meio ambiente, num esforço sinérgico de busca e reflexão do humano. Portanto, sustenta-se que a Bioética pode apresentar respostas à interrogação do "para quê" da educação e sustentá-las com responsabilidade a partir da ressignificação dos valores éticos fundamentais. Desde que o mundo é mundo houve múltiplas maneiras de se tentar uma educação efetivamente humana. Um projeto concreto para atender a essa problemática deve se propor a: ensinar sobre culturas dos diferentes com o objetivo de aproximar os homens na mutua compreensão; ensinar também sobre os direitos humanos; por fim, ensinar sobre a urgência de preservar o meio ambiente.

\section{REFERÊNCIAS}

ALVES, Marcos Alexandre. Os valores (Bio)Éticos na vida e na prática docente. Revista Teias (UERJ. Online), v. 17, p. 78-94, 2016.

ALVES, Marcos Alexandre; ROCHA ALVES, Carla Regina. O supervisor educacional como articulador da ética no contexto escolar. Revista Contrapontos, v. 12, n. 2, p. 196-206, jun. 2012.

ANJOS, Marcelo Fabri. Bioética: abrangência e dinamismo. In: Barchifontaine, C.P.; Pessini, L. (Orgs.). Bioética: alguns desafios. São Paulo: Loyola, 2001, p. 17-34.

BEAUCHAMP, Tom L. \& CHILDRESS, James F. Princípios de ética biomédica. São Paulo: Loyola, 2002.

CARVALHO, Isabel Cristina de Moura. Educação ambiental: a formação do sujeito ecológico. São Paulo Cortez, 2004.

CLOTET, Joaquin. Bioética: uma aproximação. Porto alegre: EDUPUC, 2003.

COBERN, Willian. Worldview teory and conceptual change in science education. International Journal Science Education. v. 80, n. 5, 1996, p. 579-610.

DURAND, Gui. Introdução geral a bioética: história, conceitos e instrumentos. São Paulo: Loyola, 2003.

DURAND, Gui. Natureza da bioética. São Paulo: Paulus, 1995.

FREITAS, Carlos Machado; PORTO, Marcelo Firpo. Saúde, ambiente e sustentabilidade. Rio de Janeiro: Fiocruz, 2006.

GARRAFA, Volnei. Reflexão sobre políticas públicas brasileiras de saúde à luz da bioética. In: FORTES, Paulo; ZOBOLI, Elma Lourdes Campos Pavone. Bioética e saúde pública. São Paulo: Loyola, 2003.

GRÜN, Mauro. O conceito de holismo em ética ambiental e educação ambiental. In: SATO, Michèle; CARVALHO, Isabel Cristina de Moura (Orgs.). Educação ambiental: pesquisa e desafios. Porto Alegre: Artmed, 2005.

GUIMARÃES, Mauro. A formação dos educadores ambientais. Campinas: Papirus, 2004.

IMBERT, Francis. A questão da ética no campo educativo. Petrópolis, RJ: Vozes, 2001.

JICKLING, Bob. Why I don't want my children to be educated for sustainable development. Journal of Environmental Education, v. 23, n. 4. 1992. 


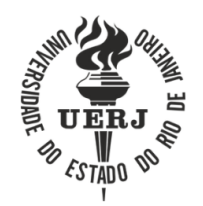

DOI:10.12957/teias.\%Y.54617

JONAS, Hans. O princípio responsabilidade: ensaio de uma ética para a civilização tecnológica. Rio de Janeiro, RJ: Contraponto, 2006.

LAYRARGUES, Philippe Pomier. Educação para a gestão ambiental: a cidadania no enfrentamento político dos conflitos socioambientais. São Paulo: 2000. LAYRARGUES, Philippe Pomier; PUGGIAN, Cleonice. A Educação Ambiental que se aprende na luta com os Movimentos Sociais: defendendo o Território e resistindo contra o Desenvolvimentismo Capitalista. Pesquisa em Educação Ambiental (Online), v. 13, p. 131-153, 2018.

LOUREIRO, Carlos Frederico Bernardo. Educação ambiental crítica: contribuições e desafios. In: MELLO, Soraia Silva; TRAJBER, Rachel. Vamos cuidar do Brasil: conceitos e práticas em educação ambiental na escola. Brasília: UNESCO, 2007. p. 65-71.

MINAYO, Maria Cecília de Souza; MIRANDA, Ary Carvalho. Saúde e ambiente sustentável: estreitando nós. Rio de Janeiro: Fiocruz, 2002.

MORIN, Edgar. A cabeça bem-feita: repensar a reforma, reformar o pensamento. Tradução: Eloá Jacobina. - 8a ed. Rio de Janeiro: Bertrand Brasil, 2000.

ORELLANA, Isabel; SUAVÉ, Lucié. A formação continuada de professores em educação ambiental: a proposta do EDAMAZ. In: SATO, Michèle; CARVALHO, Isabel Cristina de Moura (Orgs.). A contribuição da Educação Ambiental à esperança de Pandora. São Carlos, RiMa, 2001.

PELICIONI, Maria Cecilia Focesi; PHILIPPI, Jr. Arlindo. Bases políticas, filosóficas e ideológicas da educação ambiental. In: Educação ambiental e sustentabilidade. Barueri, SP: Manole, 2005.

POTTER, Van Rensselaer. Bioethics, Bridge To The Future. Englewood Clffs, NJ: Prentice Hall, 1971. POTTER, Van Rensselaer. Bioética Global e Sobrevivência Humana. In: BARCHIFONTAINE, Cristian; PESSINI, Léo. Bioética: alguns desafios. São Paulo: Loyola, 2001.

SAUVÉ, Lucie. Uma cartografia das correntes em educação ambiental. In: SATO, Michèle; CARVALHO, Isabel Cristina de Moura (Orgs.). Educação ambiental: pesquisa e desafios. Porto Alegre: Artmed, 2005.

SAWAIA, Bader Burihan. O sentido ético-político da saúde na era do triunfo da tecnobiologia e do relativismo. In: GOLDENBERG, Paulete; MARSIGLIA, Regina Maria Giffoni; GOMES, Mara Helena de Andréa (Orgs.). O clássico e o novo: tendências, objetos e abordagens em ciências sociais e saúde. Rio de Janeiro: Fiocruz, 2003.

VERMERSCH, Dominique.; MATTHEE, Marielle. Princípio de precaução e preocupação ética: um casamento racional? In: ZANONI, Magda (Orgs.). Desenvolvimento e meio ambiente: riscos coletivos, ambiente e saúde. Curitiba: Editora UFPR, 2002.

Submetido em setembro de 2020 Aprovado em marco de 2021

\section{Informações do autor}

Marcos Alexandre Alves

Universidade Franciscana - UFN, Santa Maria, RS

marcosalves@ufn.edu.br

https://orcid.org/0000-0002-5271-0624

http://lattes.cnpq.br/1846296125125082 